\title{
A Study on the Dwelling Unit Pattern For the Home-based Elderly Residents
}

\author{
CHEN Bing-Li \\ Inner Mongolia University of Science and Technology, Baotou, China \\ chenbingli2007@126.com
}

Keywords: Home-based elderly care, dwelling unite pattern, diversification

Abstract. A possibility of a new pattern for the dwelling unit for the home-based elderly residents is discussed and the diversification of the residence design is suggested after a study over the current situation in which the dwelling unit design falls into a similar pattern.

\section{Introduction}

China will witness a population of more than 1.36 billion among which the population over 60 will reach 0.202 billion making $14.9 \%$ and those over 0.65 billion that makes $9.7 \%$ by 2013 , meaning every 1000 aged citizens will share 24.4 beds in the facilities catering to the serviced for the elderly people, according to a report issued by National Bureau of Statistics of China[1].

An analysis points out that the Chinese elderly care service system will see a transform into a new composition in the coming five years in which $90 \%$ will receive the elderly care in their homes, $7 \%$ depend mainly on the community elderly care while the rest $3 \%$ will receive the institutional elderly care. The home-based elderly care system will become the main stream elderly care system in the future, according to the report based on the study on the current Chinese elderly care service system that consists mainly of homes-based elderly care, community elderly care and institutional elderly care[2].

\section{A study on the dwelling unite pattern for the home-based elderly care}

In the past, the elderly people in the home-based elderly care frame can choose living alone or living with children. "Living alone" means the elderly can take care of themselves living in their own living space, this enables them an independent life in a totally detached living space; while "living with children" means the elderly share a living space with their children and they are taken care of by their next generation, among the latter, a large percentage can not take care of themselves, they share a living with their children.

Along with the aging of the population and the relevant policies issued by the government, there is a new tendency in the architecture design that the needs of the elderly residents are put into consideration, some developers have also improved the facilities and spaces in their new projects aiming to the elderly residents, some researchers have made great efforts to explore the possibilities in improving the residence design according to the physical and psychological needs of the elderly residents.

Study shows that "living alone" is a majority among the home-based elderly care dwellers in China, while living with children makes the second largest choice. Predictions say that along with the social development and the improvement of the living standard, there will appear some new pattern as living by (beside) children and co-living with children, all these new patterns will show its social acceptance, popularity and advantage as the only-child generation begin to shoulder the responsibility of taking care of their parents.

The chart below is a comparison between the architecture designs providing the elderly people with living with ( shown in figure 1), living by ( shown in figure 2) and co-living ( shown in figure3) patterns. 
Figure 1: plan of the "Living with"dwelling unit (3E-1)

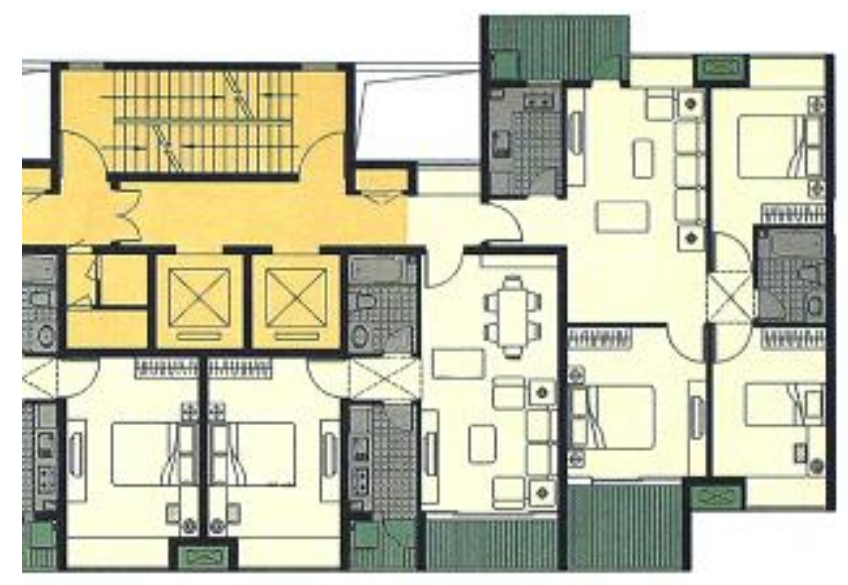

Figure2: Plan of Living by" dwelling unit (1E-1 for aged dwellers, 3E-1 for next generation)

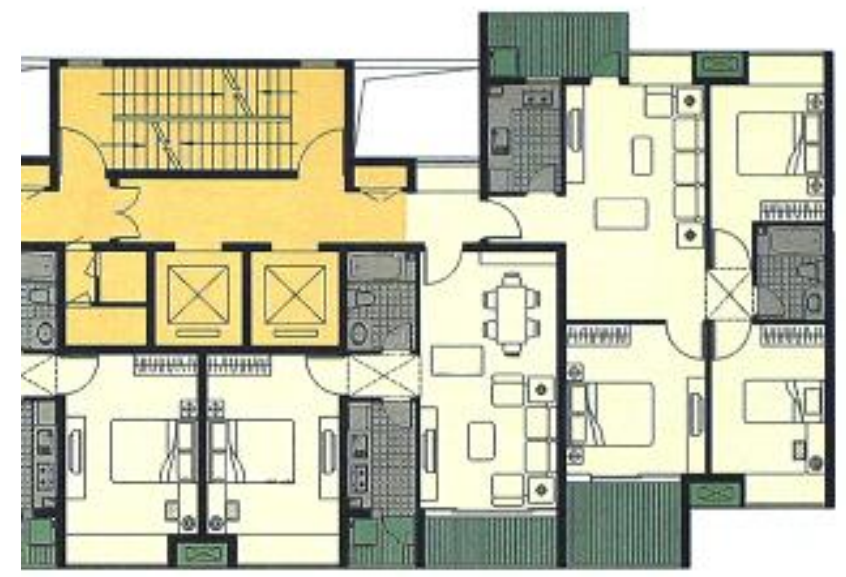

Figure 3: plan for "co-living" dwelling unit (area in the doted line, 1E-1 for aged dwellers, 3E-1 for next generation)

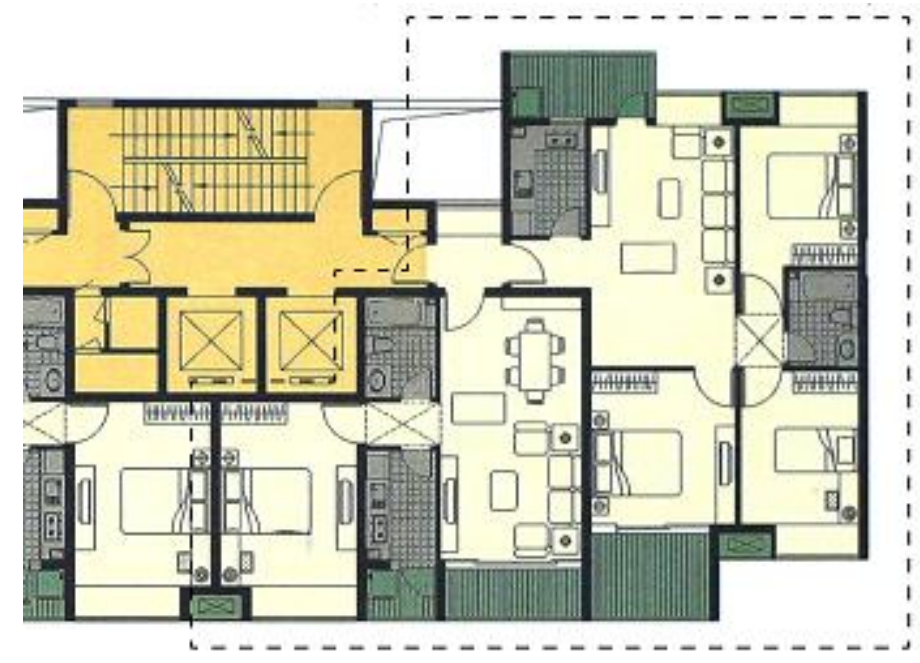


A comparison of three elderly dwellings

\begin{tabular}{|c|c|c|c|}
\hline Pattern & Living with & Living by & Co-living \\
\hline $\begin{array}{l}\text { Feature of } \\
\text { the space }\end{array}$ & $\begin{array}{l}\text { Enlarged space in } \\
\text { bed rooms. }\end{array}$ & $\begin{array}{l}\text { Two neighboring } \\
\text { detached houses. }\end{array}$ & $\begin{array}{l}\text { Two independent apartments } \\
\text { sharing a main entrance. } \\
\text { Convertible }\end{array}$ \\
\hline Advantage & $\begin{array}{l}\text { Economic } \\
\text { Multi functional } \\
\text { space. } \\
\text { Accessible in the } \\
\text { market. }\end{array}$ & $\begin{array}{l}\text { Independent space,less } \\
\text { disturbance. } \\
\text { Accessible in the } \\
\text { market. }\end{array}$ & $\begin{array}{l}\text { Separate apartments ensure } \\
\text { an independent living space } \\
\text { while neighboring children are } \\
\text { made accessible into the } \\
\text { elderly's life. } \\
\text { Closer than a neighbor, } \\
\text { psychologically safer. }\end{array}$ \\
\hline disadvantage & $\begin{array}{l}\text { Disturbance in } \\
\text { daily life. } \\
\text { Can be over } \\
\text { attended. } \\
\text { Lack of facilities. }\end{array}$ & $\begin{array}{l}\text { Generally larger, less } \\
\text { economic. } \\
\text { Lack of facilities. }\end{array}$ & $\begin{array}{l}\text { Less choices in the current } \\
\text { market due to new concept. }\end{array}$ \\
\hline $\begin{array}{l}\text { Market } \\
\text { analysis }\end{array}$ & $\begin{array}{l}\text { Increasing } \\
\text { demand in the aging } \\
\text { society. }\end{array}$ & $\begin{array}{l}\text { Increasing demand } \\
\text { Along with Well-being } \\
\text { of the aging population. }\end{array}$ & $\begin{array}{l}\text { Increasing demand along with } \\
\text { social evolution and demand for } \\
\text { human oriented design. }\end{array}$ \\
\hline
\end{tabular}

\section{Summary}

There is not enough emphasis being put into the home-based elderly care market by the land developers and housing providers in China, as the result, the limited number of the dwelling unites designed specially for the elderly residents can only be found in certain concentrated areas. Theory and experiences have proven that the over concentrated apartments for the elderly residents are not the best solution for both the developer and residents. A combination of the home-based elderly care apartment and the ordinary apartments can provide a good basis for those who need "Living with", "living by" and co-living dwelling pattern and can be more convenient for the dwellers.

In addition, the architecture design for the elderly dwellers is at its beginning, the equipment and facilities in the apartments designed for the elderly residents are still far from being enough, there are still many aspects to be improved.

Scholars point out that to achieve the diversification of the architecture design, it is necessary to probe new possibilities for the elderly residents, with the effort from the governmental level, social level and technical level, a better result in the architecture industry for the home-based elderly care can be achieved in a faster pace.

\section{References}

[1] Statistical Communiqué of the People's Republic of China on the 2013 Social Development, Ministry of Civil Affaires, June 17, 2014

[2] The unknown business Model of Elderly Care industry, on Economic Herald, digital version, by Qi Chen, February 19, 2014

http $/ /$ paper.dzwww.com/jjdb/data/20140219/html/12/content_2.html

[3] Code for design of residential building for the aged (China Architecture \& Building Press, Beijing , 2003) 
[4] Code for Design of Building for the Elderly (Science Press, Beijing, 1999)

[5] Figure1-3, Prize Winning Works of China Renovation 90 Medium-and-Small-Size Residence Design Contest 